advantages as a screening method, and remains the best single test which does not require an experienced ophthalmologist to perform it.

All surveys produce the problem of borderline cases, and this problem with glaucoma surveys has been previously discussed by one of us (Perkins, 1966). No easy solution can be proffered, and only further research will provide clearer indications of methods of reducing the number of patients requiring long-term follow-up.

\section{Summary}

A glaucoma screening survey using applanation tonometry was carried out on 5,941 persons in Bedford. The distribution of ocular tensions showed a divergence from a Gaussian curve for tensions of $21 \mathrm{~mm}$. $\mathrm{Hg}$ and above. Age, sex, time of day, and menstruation were found to influence the tonometric readings. Fifty-five cases of primary glaucoma $(0.93 \%$ of those screened) were detected as a result of the survey; these included 42 cases of chronic simple glaucoma, 3 cases of lowtension glaucoma, and 10 cases of closed-angle glaucoma. An additional 180 persons (3\% of the population studied) were found to have applanation tensions of $21 \mathrm{~mm}$. $\mathrm{Hg}$ or more but without other evidence of glaucoma. Nearly $80 \%$ of the patients with glaucoma were over 60 years of age, suggesting that glaucoma detection programmes should concentrate on the older age groups. As over $10 \%$ of the population screened required further investigation, large-scale screening of the population would throw a heavy burden on the ophthalmological services of the country. In spite of the difficulty of interpreting tonometric results, tonometry is the most reliable screening procedure which does not require an experienced ophthalmologist to perform it.

We should like to acknowledge the skilful technical assistance of Miss E. Verkoczy, Mrs. M. Williams, and Mrs. M. Setchell, and the help of the staff of the Bedford Health Department in organizing the clinic and providing secretarial assistance. Much of the initiative and planning of this survey was inspired by the late Dr. C. L. Sharp, whose untimely death occurred before the completion of the survey.

\section{REFERENCES}

Alper, M. G. (1963). Arch. Ophthal., 69, 455.

Armaly, M. F. (1965). Arch. Ophthal., 73, 11.

Davanger, M. (1965). Intraocular Pressure in Normal Eyes and in Eyes

with Glaucoma Simplex. Bergen.
Graham, P., and Hollows, F. C. (1964). Trans. ophthal. Soc. U.K., 84 597.

Grant, W. M., and English, F. P. (1963). Arch. Ophthal., 69, 314.

Hollows, F. C., and Graham, P. A. (1966). In Glaucoma, edited bv L. B. Hunt, p. 24 . London.

Hunt, L. B. (editor) (1966). Glaucoma. London.

Leydhecker, W. (editor) (1967). Tutzing Symposium on Glaucoma

Basel.
Luntz, M. H., Sevel, D., and Lloyd, J. P. F. (1963). Brit. med. J., 2. 1237.

Paterson, G. D. and Miller, S. J. H. (1963). Brit. F. Ophthal., 47, 129

Perkins, E: S. (1959). In Glaucoma, edited by F. W. Newell, p. 143 New York.

Perkins, E. S. (1966). Trans. ophthal. Soc. U.K., 86, 199.

Perkins, E. S. (1967). Atti LI Congr. Soc. oftal. ital. In press.

Pettit, T. H., and Keates, E. U. (1963), Arch. Ophthal., 69, 438. (1964). Eye Ear Nose Thr. Mth., 43 No. $6, p_{i} 53$.

Rodman, H. I. (1963). Arch. Ophthal., 69, 445.

Wolff, S. MacK., and Zimmerman, L. E. (1962). Amer. F. Ophthal., S4

Wright, J. E. (1966). In Glaucoma, edited by L. B. Hunt, p. 12 London.

\title{
Effects of Two Slimming Drugs on Sleep
}

\author{
IAN OSWALD,* M.A., M.D., D.SC., D.P.M. ; HENRY S. JONES, † M.B., B.S. ; JANENE E. MANNERHEIM,
}

Most slimming pills are also "pep-pills" and invite abuse. Past experience leads to scepticism when claims are made that a new appetite-reducing drug does not affect altertness or mood.

One may take the example of diethylpropion, reported by Seaton et al. (1961) from Edinburgh to be an effective appetite reducer with "no evidence of undue central nervous stimulation or insomnia. . . . No important side-effects." Time, however, showed that diethylpropion, like dexamphetamine and phenmetrazine, was a pep-pill, causing elevation of mood and of the pace of thinking (Jonsson et al., 1965). Despite spirited defence (Roebuck, 1963) it has become recognized as a drug which can lead to tolerance, dependence, abuse, and psychotic manifestations (Clein and Benady, 1962 ; Kuenssberg, 1962 ; Caplan, 1963 ; Jones, 1968), selling in the illicit market at a slightly lower price than amphetamine (Kuenssberg, 1963) and being included in the Drugs (Prevention of Misuse) Act, 1964.

The Edinburgh group have since reported on the effective new slimming drug fenfluramine, again reporting " no evidence of stimulation of the central nervous system " (Munro et al., 1966), while Traherne (1965) and Spence and Medvei (1966) reported no insomnia despite an evening dose.

- Department of Psychiatry, University of Edinburgh, Scotland (to which address reprint requests may be sent); formerly Visiting Professor of Psychiatry, University of W Western Australia.

+ State Mental Health Services, Heathcote Hospital, Western Australia. $\$$ Monash University Medical School, Victoria, Australia.

\section{Aims and Methods}

Experiments were conducted to determine what effect clinical doses of fenfluramine, and diethylpropion of believed equivalent anorexiant potency, would have on the sleep of paid healthy young adult volunteers when taken in the evening. Volunteers were studied in pairs. Tablets of identical appearance were used containing placebo or diethylpropion $50 \mathrm{mg}$., or fenfluramine $40 \mathrm{mg}$., always taken one to one and a half hours before lights-out. Silver disc electrodes were affixed to the scalp and face for recording the electroencephalogram (E.E.G.) and eye movements as in previous drug studies (Oswald and Thacore, 1963 ; Oswald and Priest, 1965). These two previous studies had been of whole-night sleep, but had shown that the essential information could have been gained from the first two hours of sleep. Consequently in the present study only the first two hours and the first three hours of sleep are considered (on two diethylpropion nights sleep totalled less than three hours). Results were not utilized from the first laboratory night of each volunteer. On the later nights the drug sequence used was: placebo, fenfluramine, fenfluramine, placebo, on four nights at weekly intervals for one volunteer, with the reverse order for the other of each pair ; and similarly for the other comparisons. Volunteers undertook to get a good night's sleep for at least two preceding nights and to abstain from alcohol.

In addition we observed the effect of giving nightly for a week phenmetrazine $50 \mathrm{mg}$. (two volunteers), or diethylpropion 
$50 \mathrm{mg}$. (two volunteers), or fenfluramine $40 \mathrm{mg}$. (the same four volunteers, using a cross-over sequence) and noting any withdrawal effects on the sleep of the succeeding two nights (no tablets). It had previously been observed that phenmetrazine withdrawal, like amphetamine withdrawal, was followed on some nights by an abnormally short delay (of under 45 minutes) between first onset of E.E.G. spindles and first rapid eye movements of paradoxical sleep (Oswald and Thacore, 1963).

The recordings were made with an Offner electroencephalograph and were subsequently analysed page by page and scored as : wakefulness (stage 0 ) or orthodox (NREM, "fore-brain" or "slow wave") sleep of stages $1,2,3$, or 4 (Dement and Kleitman, 1957 ; Williams et al., 1964), or paradoxical (REM, 1-REM rapid eye movement, "dreaming," or "hind-brain") sleep.

Stage 1 sleep is characterized by irregular low-voltage E.E.G. rhythms with prominence of 2-7 c.p.s. waves. In stage 2 characteristic bursts of 12-14 c.p.s. waves, most pronounced anteriorly, make their appearance, and high-voltage slow-wave complexes interrupt the generally low-voltage E.E.G. rhythms. In stage 3 rhythms slower than 2 c.p.s., with an amplitude of 75 microvolts or more, occupy $20-50 \%$ of the recording. The sleeper may then pass gradually into stage 4 sleep, arbitrarily defined as having more than $50 \%$ of the E.E.G. record made up of waves slower than 2 c.p.s. and of greater than 75 microvolts. In stage 1 the eyes make slow rolling movements, but in stages 2, 3, and 4 the eyes are motionless. The transition into a phase of paradoxical sleep is abrupt. The spindle activity and high-voltage slow waves disappear, though characteristic "saw-toothed" waves at 2-3 c.p.s. often occur in brief bursts anteriorly just before the jerky rapid eye movements that are the most striking feature of this phase.

The time from lights-out to sleep onset was noted, sleep onset seing taken as the first E.E.G. spindles of stage 2 sleep. Thereafter all stages of sleep were accumulated to make the first two hours or three hours of sleep, and the total minutes of wakefulness which intervened were noted. Thus on one diethylpropion night a total of three hours of sleep was not achieved until three hours and 26 minutes after the first onset of stage 2 sleep spindles because of 11 intervals of wakefulness totalling 26 minutes. Wakefulness was judged to be present on the basis of the E.E.G., with posterior alpha rhythms, blinking or saccadic eye movements, and muscle artifact. Shifts from other sleep stages to stage 1 usually began with brief muscle artifact and diffuse rhythms of alpha frequency mixed with slower waves and with rolling eye movements and low-voltage 4-6 c.p.s. E.E.G. waves continuing for a time before return of spindles. Also noted was the delay between first onset of stage 2 spindles and first rapid eye movement of the first period of paradoxical sleep; the number of shifts from sleep to wakefulness; and the number of shifts directly into stage 1 orthodox sleep (or drowsiness) from any other sleep stage (as opposed to shifts from stage 0 to stage 1 ). The scores so obtained were subjected to statistical analysis by $\mathrm{Mr}$. N. Stenhouse, biostatistician to the Raine Foundation of the University of Western Australia, using paired differences $t$ tests. All statistically significant findings and points of interest are summarized below.

\section{Placebo v. Fenfluramine}

Six volunteers provided 12 nights on each kind of tablet. Sleep was altered by the drug. The number of shifts direct to stage 1 sleep (drowsiness) from other stages of sleep was increased for every subject, and averaged 4.8 on placebo nights during the first three hours of sleep but 9.8 on fenfluramine $(\mathrm{P}<0.01)$. The effect in the first two hours alone was also significant $(P<0.05)$. The number of shifts from sleep to wakefulness was not significantly altered. There was no apparent effect on delay to first onset of sleep.

Data available for an additional five nights on each tablet from three subjects can legitimately be used (from the with- drawal effect study and one other abortive series). Placebo nights had preceded fenfluramine nights, so that any disturbing effects of the drug would, if at all, be countered by greater restlessness on nights when subjects were less accustomed to the laboratory.

With the combined data (Fig. 1), shifts to stage 1 were again increased $(P<0.001)$. The proportion of sleep spent in stage 1 was more than trebled $(P<0.05)$ in the first three hours at the expense of sleep stages 3 and 4 , which, taken together, were significantly reduced $(P<0.01)$; the reduction in stage 3 taken by itself being significant $(P<0.05)$. The reduction in stages 3 and 4 combined was also significant in the first two hours $(P<0.05)$. Time spent in stage 0 , delay in falling asleep, and delay between sleep onset and rapid eye movement onset were not significantly increased. The drug had no effect on time in paradoxical sleep, which in the first three hours averaged $14.2 \%$ on placebo nights and $14.8 \%$ on fenfluramine.

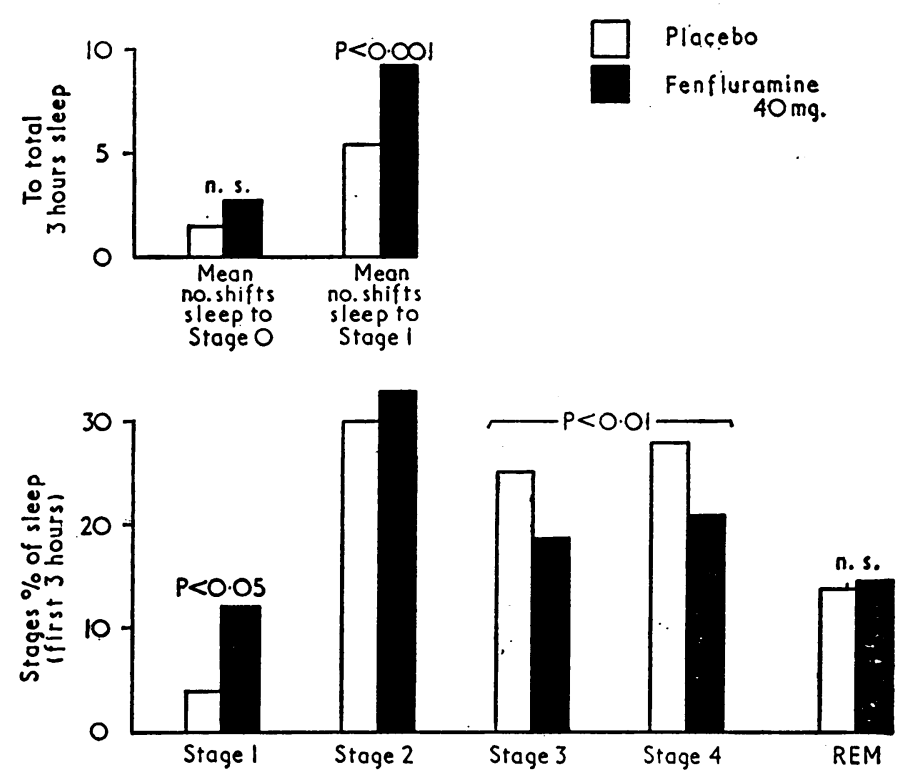

FIG. 1.-Fenfluramine increases the proportion of sleep spent in stage 1 orthodox sleep (drowsiness) and causes frequent shifts thereto. There is a concomitant reduction of stages 3 and 4 . No effect on paradoxical

(REM) sleep. Results are from 17 nights under each condition.

\section{Placebo v. Diethylpropion}

Four subjects provided eight nights on each kind of tablet. Sleep was considerably affected by the drug (Fig. 2). The number of shifts to stage 1 sleep was again more than trebled, from a mean of 3.9 to a mean of 13.3 in the first three hours $(P<0.05)$. The last is a minimum figure, since two nights on diethylpropion did not quite attain three hours of sleep. The proportion of sleep spent in stage 1 increased from $2.7 \%$ to $10.7 \%$ of the first three hours $(P<0.05)$.

The number of awakenings was increased $(P<0.05)$ for both the first two and the first three hours, in the latter rising from an average of 0.9 to 6.2 ; again a minimum figure. The time spent in stage 0 was increased $(P<0.01)$, the total duration of wakefulness after first falling asleep, and before a total of three hours of sleep was achieved, rising from an average of under 40 seconds to an average of 25 minutes.

The delay to sleep onset was unaffected, but there was a suppression of paradoxical sleep. In the first two hours it was seen only twice after diethylpropion, for six and four minutes respectively, but had averaged 10.3 minutes over the eight nights on placebo-the reduction was significant $(\mathbf{P}<0.01)$. The longest delay from sleep onset to rapid eye movements on placebo was 90 minutes, while the shortest on the drug was 91 minutes, and in four cases it did not appear at all in the first three hours. If these last delays are taken as 180 minutes 
the delaying effect of the drug was significant $(P<0.01)$. Though the mean time spent in stages 3 and 4 was less, this did not achieve significance, but time spent in stage 2 was significantly increased $(P<0.05)$ in the first two and first three hours.
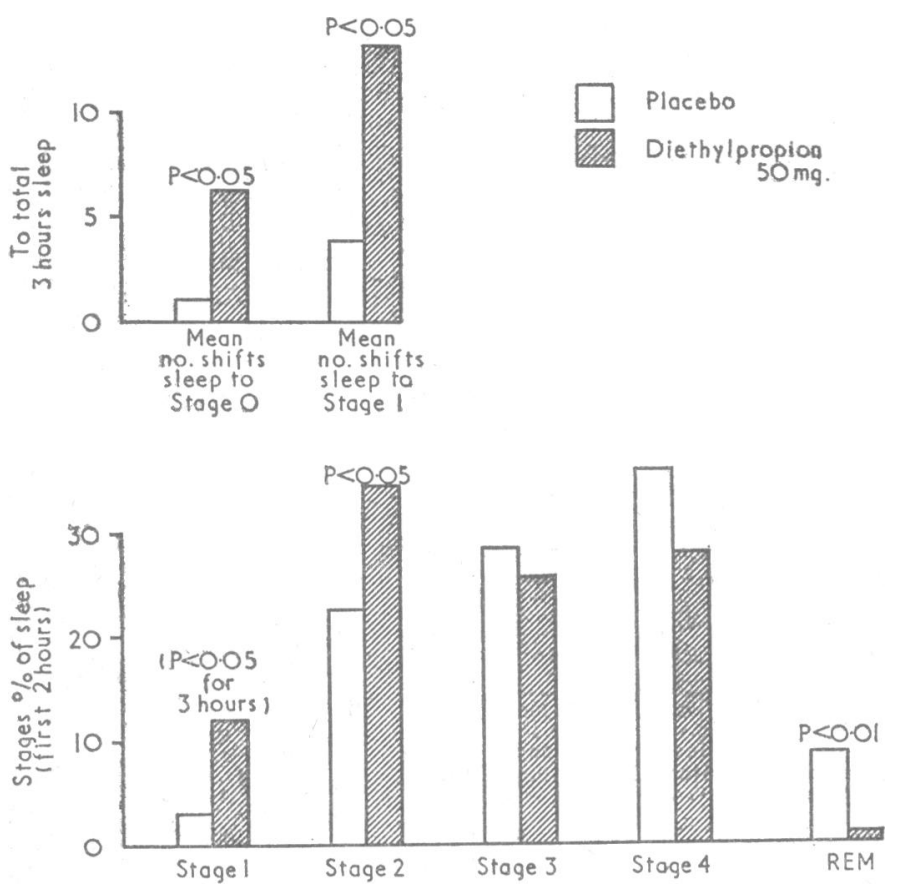

Fig. 2.-Diethylpropion causes frequent awakenings (shifts to stage 0), causes increased shifts towards and time in stage 1, and sharply suppresses paradoxical sleep. Results are from eight nights under each condition. As the full three hours were not available on two diethylpropion nights, the percentages refer to the first two hours of accumulated sleep. During the two hours the increased time in stage 1 did not quite reach the the two hours the increased time in the minimum data available it did criterion of significance (but with even the minimum from Fig. 1 will be seen so for the first three hours). Note: a difference from Fig. 1 wall at the in the placebo night sleep stage percentages, but this is normal-at the start of a night stage 4 is always maximal

\section{Fenfluramine v. Diethylpropion}

Four subjects provided eight nights on each drug. Diethylpropion caused more frequent awakenings $(P<0.01)$ and more time in stage $0(\mathrm{P}<0.01)$. Though there were more shifts to stage 1 on diethylpropion the difference was not significant $(\mathbf{P}=0.07)$.

Diethylpropion by comparison with fenfluramine reduced time in paradoxical sleep $(\mathrm{P}<0.01)$ and delayed its onset $(\mathrm{P}<0.01)$ and caused more time to be spent in stage $2(\mathrm{P}<0.05)$. The time in stages 3 and 4 differed only negligibly.

\section{Withdrawal Effect}

After seven consecutive nights on phenmetrazine, on one of the four withdrawal nights paradoxical sleep began after a zero delay (sleep onset paradoxical sleep with rapid eye movements). After seven consecutive nights on diethylpropion, on one of the four withdrawal nights the delay to first rapid eye movements was also abnormally brief-namely, 25 minutes. After ments waramine no such abnormalities were present on any of a total of eight nights.

It should be added that recordings of sleep on the phenmetrazine nights had indicated a more severe sleep disturbance than with either of the other two drugs, and had included suppression of paradoxical sleep.

\section{Discussion}

Our main experiments show diethylpropion to be a "stimulant" and to cause three principal abnormalities of sleep:
(1) frequent awakenings, (2) suppression and delay of paradoxical sleep, and (3) frequent shifts into and increased time in stage 1 sleep (drowsiness). Fenfluramine caused neither of the first two abnormalities, but did cause frequent shifts into stage 1 sleep and increase of time spent in it. If slimming pills are to be used our experiments would suggest that fenfluramine is to be preferred to diethylpropion.

It is now realized that there are two physiologically distinct kinds of sleep (Jouvet, 1965 ; Oswald, 1966). One of these, paradoxical (R.E.M.) sleep, is dramatically suppressed by amphetamine and phenmetrazine (Oswald and Thacore, 1963 ; Rechtschaffen and Maron, 1964) and diethylpropion. Fenfluramine, though rivalling diethylpropion in causing shifts from sleep into drowsiness, had no effect on paradoxical sleep, there being no delay, no suppression, and no suggestion of withdrawal effect. We conclude that in their central action these drugs differ not quantitatively but qualitatively.

Hill and Turner (1967) found fenfluramine to have no effect on critical flicker frequency in contrast to amphetamine, phenmetrazine, and diethylpropion, again suggesting a qualitatively different central action in man.

Each of the effects demonstrated must be regarded as adverse. Selective loss of paradoxical sleep, such as diethylpropion causes, is followed by, for example, abnormal cortical responses to incoming sensory information (Dewson et al., 1967) and subsequent selective compensation (Dement, 1960). In the case of orthodox (N.R.E.M.) sleep, fenfluramine caused a significant loss of its more extreme form-namely, stages 3 and 4. Though the latter loss after diethylpropion did not reach statistical significance one has to remember the suppression of paradoxical sleep and the extra time available for stages 3 and 4. Had our number of nights been greater, diethylpropion would also probably have been found significantly to reduce stages 3 and 4 . Loss of these stages with their high-voltage very slow E.E.G. waves must be regarded as undesirable; Dement and Greenberg (1966) and Berger and Oswald (1962) have reported work indicating that in restitutive value they are "worth more" than stage 1 or 2 .

While some have argued that only persons with initial personality disorders will become dependent on pep-pills, others indict the drugs themselves (Kalant, 1966). Though the capacity to suppress paradoxical sleep is not to be equated with capacity for causing dependence, nevertheless of the easily accessible substances which do quickly bring about escape from reality and which commonly cause dependence, and which have so far also been studied, all cause suppression of paradoxical sleep and rebound increase, or abnormally early onset, on withdrawal-in particular, alcohol (Gresham et al., 1963 Yules et al., 1966; Gross et al., 1966; Greenberg and Pearlman, 1967), amphetamine and phenmetrazine (Oswald and Thacore, 1963 ; Rechtschaffen and Maron, 1964), diethylpropion as now shown, methyl phenidate (Baekeland, 1966), and barbiturates (Oswald et al., 1963 ; Oswald and Priest, 1965). Among other psychotropic drugs which lead to dependence are the diazepines-for example, chlordiazepoxide (Guile, 1963) and diazepam (Barten, 1965) - and also tranylcypromine (The Times, 1967). At least one member of the diazepine groupnamely, nitrazepam (Oswald and Priest, 1965)-suppresses paradoxical sleep ; tranylcypromine does likewise (Le Gassicke et al., 1965), with rebound on withdrawal of either.

Paradoxical (R.E.M.) sleep is a different physiological condition and is that in which dreaming especially occurs-a state accompanied by escape from reality and by characteristic emotional qualities (Foulkes, 1962). The relations between this state, its suppression, and the waking psychological state are still unsettled, but the present evidence does suggest that, as Williams and Williams (1966) put it, "a chronic deficit in stage R.E.M. leads to personality disorders, whereas chronic loss of slow-wave sleep [orthodox sleep, especially stages 3 and 4] leads to impaired performance." 
The observed qualitative difference between fenfluramine and older slimming drugs known to cause dependence therefore serves somewhat to strengthen the belief that fenfluramine will prove not to induce dependence.

\section{Summary}

Slimming pills are often pep-pills. Electrophysiological recordings of nocturnal sleep showed that diethylpropion caused (1) frequent awakenings, (2) suppression of paradoxical (R.E.M.) sleep, and (3) frequent shifts into and increased time in stage 1 sleep (drowsiness). Fenfluramine caused neither (1) nor (2) but caused frequent shifts into and increased time in stage 1 sleep at the expense of stages 3 and 4 . Since fenfluramine caused no delay in the appearance of paradoxical sleep, no suppression, and no hint of withdrawal rebound, it would appear to be qualitatively different from diethylpropion.

All the abnormalities caused by the drugs must be regarded as adverse, but on these grounds fenfluramine would be preferred to diethylpropion. Furthermore, fenfluramine does not share effects on sleep of other drugs which commonly induce dependence.

We thank Mr. N. Stenhouse for the statistical analyses; Dr. R. M. Ellison, Superintendent of Heathcote Hospital, for facilities and his co-operation; and, of course, our subjects. We are indebted to Drug Houses of Australia Ltd. for the special tablets and other assistance.

\section{REFERENCES}

Baekeland, F. (1966). Psychopharmacologia (Berl.'), 10, 179.

Barten, H. H. (1965). Amer. 7. Psychiat., 121, 1210

Berger, R. J., and Oswald, I. (1962). J. ment. Sci., 108, 457.
Caplan, J. (1963). Canad. med. Ass. 7., 88, 943.

Clein, L. J., and Benady, D. R. (1962). Brit. med. 7., 2, 456

Dement, W. (1960). Science, 131, 1705.

Dement, W., and Greenberg, S. (1966). Electroenceph. clin. Neurophysiol., 20, 523.

Dement, W., and Kleitman, N. (1957). Electroenceph. clin. Neurophysiol., 9,073 .

Dewson, J. H., Demen

Science, 156, 403.

W.

Foulkes, W. D. (1962). 7. abnorm. soc. Psychol., 65, 14.

Greenberg, R., and Pearlman, C. (1967). Amer. F. Psychiat., 124, 133. 140, 1226 .

Gross, M. M., et al. (1966). \%. nerv. ment. Dis., 142, 493.

Guile, L. A." (1963). Med. F. Aust., 2, 56.

Hill, R. C., and Turner, P. (1967) \%. Pharm. Pharmacol., 19, 337. Jones, H. S. (1968). Med. \%. Aust., 1, 267.

Jonsson, C. O., Sjöberg, L., and Vallbo, S. (1965). Scand. F. Psychol.,

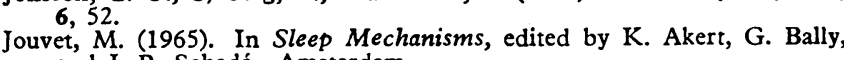
and J. $P_{j}$. Schadé. Amsterdam.

Kalant, O. J. (1966). The Amphetamines: Toxicity and Addiction. Toronto.

Kuenssberg, E. V. (1962). Brit. med. 7., 2, 729.

Kuenssberg, E. V. (1963). Brit. med. \%., 2, 1406.

Le Gassicke, J., Ashcroft, G. W., Eccleston, D., Evans, J. I., Oswald, I., and Ritson, E. B. (1965). Brit. Y. Psychiat., 111, 357.

Munro, J. F., Seaton, D. A., and Duncan, L. J. P. (1966). Brit. med. 7., 2,624 .

Oswald, I. (1966). Sleep. Harmondsworth, Middlesex.

Oswald, I., Berger, R. J., Jaramillo, R. A., Keddie, K. M. G., Olley, P. C. and Plunkett, G. B. (1963). Brit. F. Psychiat., 109, 66.

Oswald, I., and Priest, R. G. (1965). Brit. med. F., 2, 1093

Oswald, I., and Thacore, V. R (1963). Brit. med. $72,2,427$.

Rechtschaffen, A., and Maron, L. (1964). Electroenceph. clin. Neurophysiol., 16, 438 .

Roebuck, B. E. (1963). Brit. med. 7., 2, 936.

Seaton, D. A., Duncan, L. J. P., Rose, K., and Scott, A. M. (1961) Brit. med. Y., 1, 1009.

Spence, A. W., and Medvei, V. C. (1966). Brit. F. clin. Pract., 20, 643.

Spence, A. Times, 1967 a 18 July,

The Times, 1967 (18 July, p. 2.

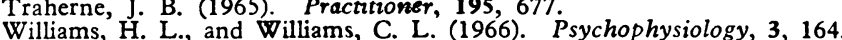

Williams, R. L., Agnew. H. W., and Webb, W. B. (1964). Electroenceph. clin, Neurophysiol, 17 . W.

Yules, R. B., Freedman, D. X., and Chandler, K. A. (1966). Electroenceph. clin. Neurophysiol., 20, 109.

\title{
Studies on Iron Absorption in Acute Liver Disease
}

\author{
HELEN BROWN, ${ }^{*}$ B.SC. ; SHEILA T. CALLENDER,* M.D., F.R.C.P. ; J. S. MALPAS, ${ }^{*} \dagger$ M.B., B.SC., M.R.C.P.
}

\section{Brit. med. F., 1968, 1, 799-801}

Patients with cirrhosis of the liver may have an increased absorption of oral iron, and in some of such cases a pancreatic extract will reduce the absorption towards normal (Callender and Malpas, 1963). These findings suggest that associated chronic pancreatic damage is an important element in the altered iron absorption in chronic liver disease, but the part played by liver damage per se is not clear. The present paper reports studies of iron absorption in patients suffering from acute hepatitis and in rats with experimental liver damage.

\section{Animal Studies}

Twenty female Wistar-strain rats weighing 170 to $200 \mathrm{~g}$. were taken at random from a batch of animals maintained since weaning on an iron-supplemented diet (Diet C, McCall et al., 1962). Ten remained on the diet as controls and 10 took the same diet with the addition of $0.1 \% \alpha$-naphthyl isothiocyanate, the approximate daily intake of which was $10 \mathrm{mg}$.

Twelve days later those on the $\alpha$-naphthyl isothiocyanate diet showed yellowness of ears, muzzle, and feet, and had lost an average of $20 \mathrm{~g}$. in weight as compared with an average gain of $17 \mathrm{~g}$. in the controls. All 20 were dosed with $1 \mathrm{ml}$.

\footnotetext{
* Nuffield Department of Clinical Medicine, Radcliffe Infirmary, Oxford.
} t Present address St. Bartholomew's Hospital, London E.C.1.

of a solution containing $250 \mu \mathrm{g}$. of ${ }^{59} \mathrm{Fe}$-labelled ferrous iron per $\mathrm{ml}$. Total body radioactivity was measured after dosing and then one week later. The diet containing $\alpha$-naphthyl isothiocyanate was fed throughout the experiment.

The results of the tests of iron absorption are shown in the Chart. The values for iron absorption in the two groups occupy the same range and have a mean absorption for

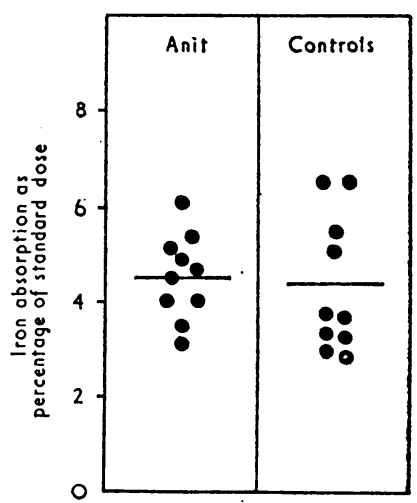

Iron absorption in rats with experimental cirrhosis of the liver caused by $\alpha$-naphthyl isothiocyanate (anit.) and in controls. $\alpha$-naphthyl isothiocvanate treated rats of $4.5 \%$ and for control rats of $4.4 \%$.

After the test of iron absorption two rats from each group were killed and examined. Micro-haematocrit examinations were done on samples of venous blood, and specimens of liver were taken for histological examination. The plasma of the treated rats was jaundiced, and these rats had lower haematocrits $(33 \%$ and $33 \%)$ than their controls $(41 \%$ and $46 \%)$. The general appearance of the liver in the treated rats was coarser 